\section{Reflections on Reswitching and Roundaboutness}

\author{
Roger W. Garrison*
}

\section{Introduction}

Controversies about capital and interest never die. But interest in the issues of technique reswitching and roundaboutness waxes and wanes-though without rhythm and without obvious provocation. Central to these issues, so says one school of thought, is the viability of the neoclassical production function and, more broadly, the viability of neoclassicism itself. Avi J. Cohen and Geoffrey C. Harcourt (2003a) have recently published an illuminating retrospective on the debate between Cambridge U.K. and Cambridge, MA. Their title question is "Whatever Happened to the Cambridge Capital Theory Controversies?" but somehow this question never quite gets answered. The reader gets the impression, however, that the authors are actually expressing annoyance if not dismay that their neoclassical adversaries have never cried uncle and scrapped their aggregate production function. Commenting on Cohen and Harcourt, Jesus Felipe and J. S. L. McCombie (2003, p. 229) ask the question in a more confrontational way: "So why is the aggregate production function still widely used in neoclassical macroeconomics, even after the legitimacy of the Cambridge, U.K.'s critique was explicitly acknowledged by Samuelson (1966a)?"

My own interest in these questions stems from several fortuitous circumstances. While a visiting fellow at the London School of Economics in May and June of 2003, I had the privilege of sitting in on a seminar conducted by Geoffrey Harcourt. The paper he presented on that occasion was the uncut version of the "Whatever Happened?" article. Extended preliminary remarks were aimed at justifying a measure of capital that puts this factor of production dimensionally at par with labor and land. Harcourt insisted that to be conformable with the other two factors, capital cannot be measured in value terms. Having set the stage with this imperative concerning dimensionality, he walked us through the rounds of

\footnotetext{
* Roger W. Garrison, Professor of Economics at Auburn University in Alabama, is the author of Time and Money: The Macroeconomics of Capital Structure (London: Routledge, 2001). Helpful comments on this paper by Roger Koppl, Thomas McQuade, Robert Murphy, Sudha Shenoy, and Sven Thommesen are gratefully acknowledged.
}

debate. While the blow-by-blow was presented with humor and charm, the reaction of the listeners was in the spirit of Felipe and McCombie-indignation that the losers (the neoclassicals) had never admitted defeat and adjusted their research programs accordingly.

In 1966, the year that MIT's Paul Samuelson published his "Summing Up" confessional, pouring gas on the anti-neoclassical fire, I was immersed in a course in Engineering Economics at the Missouri School of Mines and Metallurgy (now the University of Missouri at Rolla). Because of the mathematical orientation of that course and its focus on the calculus of present values and internal rates of return, my classmates and I were fully aware of the possibility of multiple internal rates of return. And as a mathematical matter, the occurrence of multiple rates emerges out of circumstances similar to those that give rise to technique reswitching, a phenomenon that lies at the heart of the Cambridge controversies. As engineering students, however, none of us was aware of the broader economic implications of movements in interest rates, let alone the supposedly threatening implications for neoclassical production theory of the paradoxical circumstance known as technique reswitching: a decline in the rate of interest could lead to the adoption of less roundabout, less capital intensive methods of production.

In the late 1970s after a switching of careers (from engineering to economics), I was invited to comment on a conference paper by Leland Yeager (1979) titled "Capital Paradoxes and the Concept of Waiting." Drawing on Gustav Cassel, Yeager dealt specifically with the issue of dimensions. If the interest rate is a price, it is the price of a factor measured in the complex units of dollar-years. As will be demonstrated in a subsequent section, this Casselian unit (dollar-years) is the straightforward result of a simple exercise in unit analysis-a procedure I had used many times over in engineering applications. Among other insights in Yeager's paper was a healthy perspective on the Cambridge controversies, making full use of the dual dimensionality of Casselian waiting. (I now realize that Harcourt and his fellow Cantabrigians would be wholly dismissive of Cassel's and Yeager's dollar-year on the grounds of its incorporating the verboten value dimension.)

My role at the conference was to provide an Austrian perspective on these troublesome issues. Dubbing my comment "W aiting in Vienna" (Garrison, 1979), I leveraged Yeager's critical account of the seemingly paradoxical techniqueswitching examples by transplanting the logic from the theory of capital to the theory of evolution. By constructing an analogously paradoxical speciesreswitching example (in which the survival of the fittest is violated at one of the switch points), I cast doubt on the wisdom of Charles Darwin. I considered the changing forms of life we might observe as we travel from the north pole to the south pole. If switching from polar bears to alligators is consistent with Darwinian theory, then switching back isn't. The intent of my parody on paradox, of course, was to question the meaningfulness of the charges leveled by Cambridge, U.K. against the Austrians. 


\section{Paradoxes and Frameworks}

In the hands of Cambridge, U.K., the capital controversies thrive on paradox. If theoretical framework $X$ entails paradoxical characteristics that seem to undercut the fundamental relationships on which it is erected, then theoretical framework $X$ should be abandoned in favor of theoretical framework $Y$. The $X$, of course, is neoclassicism-with due attention to the temporal dimension of production processes. Böhm-Bawerk's notion of roundaboutness and the related notion of capital intensity are central to the paradoxes. The $Y$-as put forth by Cohen and Harcourt (2003a, pp. 207ff)-is the classical political economy of David Ricardo and Piero Sraffa, where the fundamental unit of analysis is the social class and where the economic problem is the distribution of the surplus. Cohen and Harcourt cite Walsh and Gram (1980), a book that dramatizes the discontinuity entailed in classicism's giving way to neoclassicism.

It is not difficult to imagine substantive answers to the confrontational question posed by Felipe and McCombie. ("Why is the aggregate production function still widely used...?") Three such answers suggest themselves: (1) The alleged paradoxes are not so paradoxical once the particulars of the trumped-up instances of them are fully understood. (2) The particular temporal profiles of reswitchingprone techniques are sufficiently quirky as to warrant neglect in setting out fundamental supply-side principles-an argument that has its parallel in the neglect of the Giffen good in setting out fundamental demand-side principles. (3) No actual instances of the paradoxical supply-side phenomena have ever been identified by the Cantabrigians-there not being even so much as a suspected instance to parallel the suspected upward-sloping demand for Giffenesque potatoes in Ireland during the mid-nineteenth-century famine.

Cohen and Harcourt did not address this third-listed answer, except for insisting that the empirical question is "beside the point: This was [and is] a theoretical debate" (p. 209). In commenting on the Cohen-Harcourt article, Felipe and McCombie $(2003,230)$ attempt to turn the tables on the neoclassicals by suggesting that empirically established regularities that seem to lend credence to the neoclassical production function may instead derive from the underlying accounting identities. Cohen and Harcourt (p. 200) are specifically unreceptive to the second-listed answer-the idea that the anomaly fueling the controversy is akin to the Giffen good. In the perspective of Cambridge, U.K, the controversy is not a Giffen-like "tempest in a teapot" but rather an identification of some "deep issues" whose lack of a satisfactory resolution call into question the viability of neoclassicism.

The first-listed answer-that understanding deflates paradox-is an non-answer as far as Cohen and Harcourt are concerned. They credit Samuelson for providing the intuition to go with the arithmetic demonstrations but question the meaning of a theoretical construction in which anomalous relationships are even a possibility.
Samuelson's (1962) "surrogate production function," whose construction precluded the possibility of the anomalies, is seen as a very special case. Cohen and Harcourt (2003a, p. 210) ask, "What is the meaning of a simple model whose clear-cut results are not sustained when restrictive assumptions are loosened?"

Though Samuelson offered some intuition about the capital paradoxes, Leland Yeager's "Toward Understanding Some Paradoxes in Capital Theory" (1976) suggested that to understand them is to resolve them. Why should some technical reckoning of roundaboutness have a claim on our attention when an economic reckoning-with due attention to both value and time-is what counts for the entrepreneurs' choices among techniques? And if the value dimension is itself affected by changes in the rate of interest, why not acknowledge this aspect of intertemporal allocation forthrightly rather than lament that our measure of the capital input is fundamentally different from our measures of labor and land-and rather than insist that all measures of inputs must be dimensionally similar despite the inherent dissimilarities of the inputs?

Robert Greenfield (2003), who sees a debate-ending resolution in Yeager's insights, is puzzled by Cohen and Harcourt's wholesale neglect of Yeager's article. In their response to Greenfield, Cohen and Harcourt (2003b, p. 232) single out this article for an unduly discourteous response. "Unlike [some articles, which constitute a "valuable complement" to their own summary article], Leland Yeager's article was omitted [from discussion] because it misunderstood the issues and did not make a meaningful contribution to the debate." Cohen and Harcourt reproduce a long paragraph from Knut Wicksell's Lectures on Political Economy (1934 [1911]) to establish that the neoclassicals understood early on about the inherent limitations in measuring the capital input: unlike labor and land, capital cannot be measured summarily, according to Wicksell, except in value terms. Cohen and Harcourt's point is that the problem of capital measurement is an "internal neoclassical problem"-and (implicit in their dismissive treatment of Yeager)-an unresolvable one.

And so, just what are the issues that Yeager misunderstood? The live issues, as suggested by the tone of Cohen and Harcourt's article and response to critics, can only be those related to the reluctance-or the intransigence-on the part of the neoclassicals in giving up a fatally flawed framework in favor of an alternative framework that, even on other grounds, is the more appealing. In short, acknowledging the possibility of technique reswitching in the neoclassical framework should lead posthaste to framework reswitching. The neoclassicals should return to the class-analysis-cum-distribution-of-the-surplus brand of classicism. Yeager had failed to understand that Cambridge U.K. was not looking for a resolution to the paradox but rather was looking to abandon the framework in which the paradox emerged.

To the three possible neoclassical responses to Felipe and McCombie listed above, there must be added a fourth. Cohen and Harcourt (p. 210) suggest that 
neoclassical production theory is "a mistake whose insights must be discarded" and that the neoclassicals should be "searching for a better explanation in a completely different direction." It is not clear, however, that neoclassicals would consider classical political economy to be the next best alternative to neoclassicism, let alone a "better explanation." In any case, what is called for, if anything, is not framework reswitching on the basis of a perceived flaw in one of the frameworks but rather an exercise in comparative analytical frameworks. Are paradoxes, ambiguities, and indeterminacies less of a problem in classical political economy than in neoclassicism? Arguably, the continuing development of the various schools of thought-classical, neoclassical, and Austrian-collectively constitutes an ongoing comparative-framework exercise.

A more manageable-and potentially more fruitful-question might be: why in the critical Cantabrigian literature are the neoclassical and Austrian schools lumped into one? Most modern expositions of neoclassicism include scant mention, if any mention at all, of Böhm-Bawerk or of any of the other Austrians. Do we suspect that the summary treatment of these two schools serves some polemical and/or strategic purpose? And can a disjoining of these schools clear the way for a more healthy understanding of reswitching and roundaboutness, possibly defusing the charges issued by Cohen and Harcourt and pointing the way to a more satisfactory treatment of the economy's supply side?

Before attempting an answer to this last question, I offer (1) an exposition of multiple internal rates of return and technique reswitching in the form of a child's guide and (2) a discussion of the issue of dimensionality, identifying a problem quite separate from-and more fundamental than-the possibility of technique reswitching.

\section{A Child's Guide to the Capital Paradoxes}

Some ideas in economics can best be presented in the form of a "Child's Guide"-not because the ideas are complex or entail great difficulty but because of they are so simple. Maddox and Carter (1982) gained attention and made headway with their "Child's Guide to Rational Expectations." They convincingly demonstrated that as the basic idea becomes transparent, its relevance to the broader issues of economics becomes questionable. And in the spirit of Cohen and Harcourt's response to critics (2003b, p. 232), the presentation below of the supposed capital paradoxes is offered partly for the benefit of "younger readers unaware of the issues involved."

It is commonplace in the literature on the Cambridge capital controversies to refer to Samuelson's celebrated "Summing Up" for a hypothetical instance of reswitching. Harcourt and Cohen (2003a, pp. 203) rely heavily on it, making full use of its round-numbers arithmetic. As indicated above, no one ever refers to an actual instance of it. The lack of any documented or even suspected instances of this supposed capital-market anomaly underlies Joan Robinson's (1975) verdict of "The Unimportance of Reswitching." Her more fundamental point is that reswitching is not something that might actually be "going on" at all; rather, the "switches" refer to critical points of comparison in a comparative-statics exercise.

Though I doubt the phrase was ever used in Engineering Economics, "comparative statics" was the order of the day. And in those days, I was not attuned to the distinction between statics and dynamics in any application outside the hard sciences. Attention to units of measurement was critical in the field of engineering, but as a major in electrical engineering, I was focused on kilowatts and kilowatthours and not on dollars and dollar-years. The professor of Engineering Economics, himself an engineer and not an economist, gave short shrift to the economics of capital and interest. His goal was simply to familiarize the students with present-value equations. Given a rate of discount, a present value could be calculated for any constellation of revenues and/or outlays. Alternatively, setting the present value equal to zero would allow for the calculation of the internal rate of return.

With little or no grounding in economics, the students could easily see that if a present value equation took the form of a polynomial of second-degree (or of some higher degree), there was the distinct possibility of multiple internal rates of return. Further, it turns out that if a single project whose break-even point (zero present value) corresponds to more than one interest rate, that project's outlays and revenues can be decomposed mathematically into two outlay-and-revenue sequences to represent two projects that exhibit the supposedly troublesome phenomenon of reswitching.

The illustrative examples I offer below differ from Samuelson's in three respects. (1) I deal first with a single project that entails multiple rates of return. (2) I work with numbers that constitute plausible interest rates: $r=2 \%$ and $r=8 \%$. (Samuelson worked with $50 \%$ and $100 \%$.) And (3) I start with the multiple rates and work backward to see what temporal characteristics the project must have. Then, having identified a temporal sequence of revenues and outlays, I can decompose the sequence into two projects that will exhibit switching and reswitching, the switch points occurring at those same two rates of interest, i.e., $r$ $=2 \%$ and $r=8 \%$.

\section{Multiple Rates of Return}

If a present-value reckoning yields two solutions for the internal rate of return, say $r=2 \%$ and $r=8 \%$, then that reckoning must ultimately resolve itself into the equation

$$
(r-0.02)(r-0.08)=0
$$

$$
r^{2}-0.10 r+0.0016=0
$$


Rewriting to express this equation in terms of the discount factor $(1+r)$, we get

$$
\begin{array}{ll}
\text { (3) } & {\left[(1+r)^{2}-2 r-1\right]-0.10 r+0.0016=0} \\
\text { (4) } & (1+r)^{2}-2.10 r-0.9984=0 \\
\text { (5) } & (1+r)^{2}-[2.10(1+r)-2.10]-0.9984=0 \\
\text { (6) } & (1+r)^{2}-2.10(1+r)+1.1016=0
\end{array}
$$

Dividing by the highest power of the discount factor $(1+r)^{2}$ puts the present-value equation in standard form:

$$
1-2.10 /(1+r)+1.1016 /(1+r)^{2}=0
$$

Finally, we can scale equation (7) by 100 so as to avoid fractions of pennies.

$$
100-210 /(1+r)+110.16 /(1+r)^{2}=0
$$

In its simplest interpretation (and taking positive and negative terms to indicate revenues and outlays, respectively), equation (8) represents a three-period project

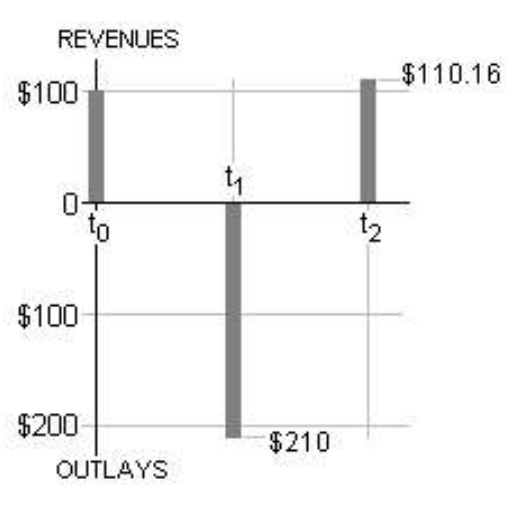

Figure 1: A Three-Period Project that entails some up-front revenue. In the initial period, $\mathrm{t}_{0}$, earnest money in the amount of $\$ 100$ is received; in the next period, $\mathrm{t}_{1}$, outlays of $\$ 210$ are made; and in the last period, $t_{2}$, the project's output is delivered and a final payment of $\$ 110.16$ is received. Figure 1 illustrates the project in terms of both time and money. By construction, this is a break-even project at interest rates of $2 \%$ and $8 \%$. At the middling interest rate of $5 \%$, the projects is in the red by $\$ 0.08$. At interest rates below $2 \%$ or above $8 \%$, the project is in the black-by $\$ 0.06$ at a $1 \%$ rate of interest and by $\$ 0.07$ at a $9 \%$ rate. The dependence of present value on the rate on interest over the range of $0 \%$ to $14 \%$ is shown in Figure 2. Note that at a zero rate of interest, the present value, which is simply the algebraic sum of the undiscounted revenues and outlays, is $\$ 0.16$.

Except in the vicinity of the switch and reswitch points, the relationship of present value to the rate of interest is well behaved. At extremely high rates of interest, where the terms containing positive powers of the discount factor become negligible, the profitability of this project approaches the initial receipt of $\$ 100$. Figure 3 shows the dependence of present value on the rate of interest for interest rates up to $1000 \%$. Note that the variations of present value in the low single digits-including the negative present values over the $2 \%$ to $8 \%$ range are too small to be discernible in Figure 3.

A mirror-image interpretation of our multiple-rate equation is produced by reversing all the signs:

$$
-100+210 /(1+r)-110.16 /(1+r)^{2}=0
$$

This three-period project requires an initial outlay of $\$ 100$ and generates revenue in the second period of $\$ 210$. The outlay of $\$ 110.16$ that occurs in the third period might be clean-up costs or costs of complying with a service contract. The break-even rates of return are still $2 \%$ and $8 \%$. But with incomes and outlays reversed, the middling interest rate of $5 \%$ puts the project in the black by $\$ 0.08$, and for all rates less than $2 \%$ or greater than $8 \%$, the project is in the red. The graph of the outlays and revenues of this mirror-image project, along with the graphs of the dependence of present value on the rate of interest, are the same as Figures 1, 2, and 3-but with the

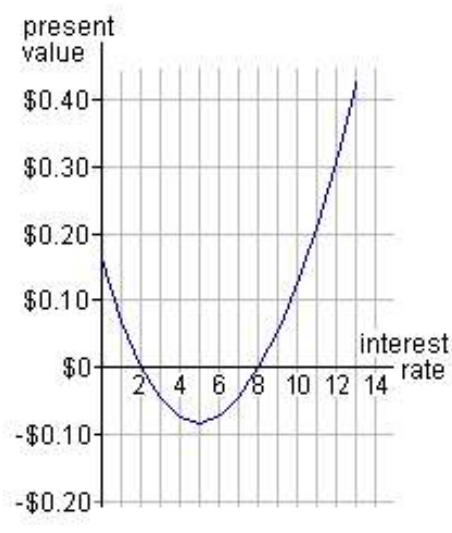

Figure 2: Present Value (0\%-14\%) positive and negative axes reversed.

Equations (8) and (9) can also represent projects where individual terms correspond to net outlays or net revenues. The term $210 /(1+r)$, for instance, might

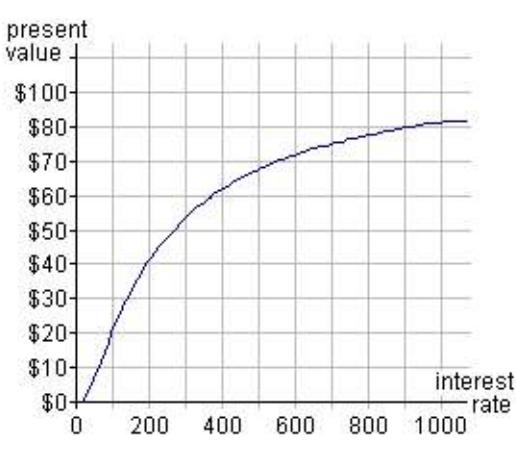

Figure 3: Present Value (0\% to $1000 \%)$ represent revenues at $t_{1}$ of $\$ 300$, partially offset in that same period by outlays of \$90. Similarly, the equations also permit outlays matched by revenues of equal magnitude in other periods, say, $t_{3}-$ at which time $\$ 50$ of revenues just offset $\$ 50$ of outlays. Essential to the projects represented by equations (8) and (9) is an interspersing of revenues and outlays. Any project for which all outlays are made before any revenues are received cannot have multiple internal rates of return.

\section{From Multiple Rates to Technique Reswitching}

The three terms in equation (9) are taken to be receipts (+) or outlays (-) that characterize a single project. Suppose, though, that we transpose the positive term 
to the other side of the equation and interpret the terms, now all of the same sign, as representing outlays-but of two alternative projects, either of which is a means of producing a given output in, say, period $t_{3}$.

$$
-100-110.16 /(1+r)^{2}=-210 /(1+r)
$$

These two projects are differ not by the nature of the inputs but only by the alternative "techniques," which are defined as particular temporal sequences of inputs. The single term on the right side of Equation (10) can represent the outlay associated with Technique A; the two terms on the left side can represent the outlays associated with Technique B. (The corresponding revenue terms are the same for the two projects and so would cancel one another if added to each side of the equation.) Equation (10) suggests that there is some rate (or rates) of interest for which the present values of the outlays are the same for both techniques.

The solution to Equation (10) is, by construction, identical to the solution to equations (8) and (9). That is, the two techniques have the same costs, reckoned as the present value of outlays, when the cost of borrowing is $2 \%$ and when it is $8 \%$. At all other rates, one technique will have a cost advantage over the other. The relative costs of the two techniques, $\mathrm{C}_{\mathrm{B}} / \mathrm{C}_{\mathrm{As}}$, is given by Equation (11)

$$
\text { (11) } \mathrm{C}_{\mathrm{B}} / \mathrm{C}_{\mathrm{A}}=\frac{100+110.16 /(1+r)^{2}}{210 /(1+r)}=\frac{100(1+r)^{2}+110.16}{210(1+r)}
$$

The general characteristics of $\mathrm{C}_{\mathrm{B}} / \mathrm{C}_{\mathrm{A}}$ as it varies with the rate of interest are revealed by inspection. At a zero rate of interest, $C_{B}$ is higher than $C_{A}$ by $\$ 0.16$, giving Technique $A$ a cost advantage. (The zero-interest value of $C_{B} / C_{A}$ is 1.000762.) We can note that Equation (11) is a continuous function for interest rates above $r=-1$ and that the cost ratio is 1.0000 at interest rates of $2 \%$ and $8 \%$.

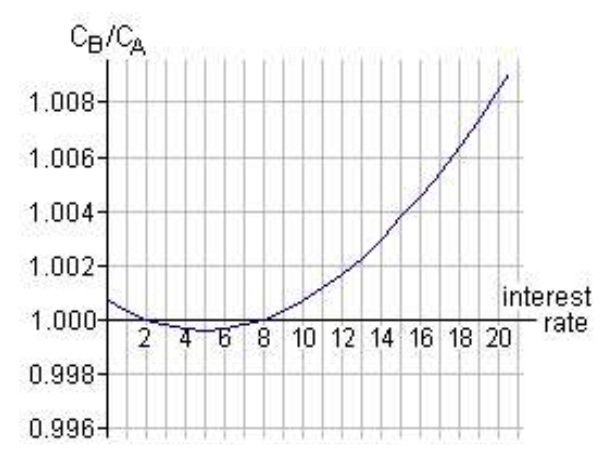

Figure 4: Cost Advantage $C_{B} / C_{A}$ Hence, as shown in Figure $4, \mathrm{C}_{\mathrm{B}} / \mathrm{C}_{\mathrm{A}}$ falls from 1.000762 to unity as the interest rate rises from $0 \%$ to $2 \%$, then dips below that level as the interest rate rises beyond $2 \%$, returning to unity at $8 \%$. Our cost ratio then rises indefinitely as the interest rate rises beyond $8 \%$. The minimum value of $\mathrm{C}_{\mathrm{B}} / \mathrm{C}_{\mathrm{A}}$ is 0.999592 , which corresponds to an interest rate of $5 \%$. Samuelson (1966a) presents a similarly shaped relative-cost curve for his two techniques, for which the equal-cost points are $50 \%$ and $100 \%$.

Now, which of the two technique-defined projects is the more capital intensive, or the more roundabout? Technique B has the earlier input, but the outlay associated with that input is only $\$ 100$. The outlay associated with the initial input of Technique $\mathrm{A}$ is $\$ 210$, but that input can occur one period later. It is precisely this kind of play off between time and money that precludes a simple answer to the question about capital intensity and roundaboutness. However, if one of the techniques is to be declared more capital intensive, more roundabout, than the other, then one of the two switchings of technique will be at odds with conventional neoclassical and Austrian wisdom. Suppose we consider Technique $\mathrm{B}$ the more roundabout. Then a decline in the interest rate from, say, $9 \%$ to $5 \%$, will provoke a switching (from Technique A to Technique B) that is consistent with the wisdom of Böhm Bawerk: a lower rate of interest favors more roundabout methods of production. But a further decline the interest rate from $5 \%$ to, say, $1 \%$ will provoke a reswitching that is contrary to that wisdom. This the anomaly that, according to the Cantabrigians, undermines the fundamentals of neoclassicism and Austrianism.

It may be worth noting that the hypothetical examples of reswitching invariably entail either implausibilities or trivialities. Samuelson's implausibly high interest rates cast doubts on the relevance of his hypothetical example. Clearly, though, Samuelson (p. 571) has little patience with those who would prefer to see the percentages that actually look like interest rates. He suggests that "The reader can think of each period as a decade if he wants to pretend to be realistic." In other words, if you don't want to think of $100 \%$ interest rates, then think of 30 -year planning horizons! But even with this way of thinking, the cost advantage of the 20 -year project is never as much as $15 \%$ unless the interest rate rises above a $200 \%$ DPR (decadal percentage rate) or falls to $0 \%$, and the cost advantage of the 30 -year project (at interest rates between $50 \%$ and $100 \%$ DPR) maxes out at about $1 \%$.

My own example features interest rates of $2 \%$ and $8 \%$ and production periods of two or three years. Using such plausible ranges for interest rates and planning horizons gives us cost advantages that are minuscule. The cost advantage of the three-year project is $0.0763 \%$ at a zero rate of interest, and the maximum cost advantage of the two-year project (at a 5\% interest rate) is $0.0408 \%$. A $15 \%$ cost difference (of the three-year project over the two-year project) doesn't occur unless the interest rate is nearly $180 \%$ APR.

The greater point in offering my own hypothetical example, which in many respects parallels Samuelson's hypothetical example, is that the framework of analysis here is not Cambridge capital theory at all but rather engineering economics. And, as we will see, my framework is heavy on engineering (or rather on present-value calculations) and light on economics. The key difference between Cambridge, U.K. and Rolla, MO (where I studied engineering) stems, once again, from the issue of the appropriate units for measuring capital. 


\section{Dimensions of Capital: Physical, Value, and Amorphous}

Adhering to the Cambridge tradition, Samuelson, Cohen, and Harcourt treat the capital input as dated labor. That is, so many worker-hours expended during a particular period constitute a capital investment. This capital investment, or several similarly defined capital investments, mature in time into consumable output. Neither dollars nor any other measure of value enters the picture. As already indicated, Cohen and Harcourt, taking to heart Wicksell's discussion of the ambiguities that arise from measuring capital summarily in value terms, insist on physical measures only. My engineering economics, then, though perfectly parallel to Samuelson's arithmetic, would be strictly illegitimate in the Cambridge view-precisely because "capital value" cannot be equated with "capital." The conflation of the value of capital and the quantity of capital is what gets the neoclassical economists in trouble.

So, what units do the neoclassicals actually have in mind for the capital in their production function? It is instructive to consult a reputable mainstream text from the Samuelson "Summing Up" era. With no additional criteria (except for the sample text's being within arm's reach of my writing desk), I choose C. E. Ferguson's Microeconomic Theory (1966). Using conventional symbols, we can write: $Q=f(K, L)$. Output is a function of capital and labor inputs. Omitting any specific temporal dimension and including labor explicitly as a second input preclude treating capital as dated labor. The capital input must be modeled in some other way. Ferguson (1966, p. 153) supplies hints about units-and, unavoidably, hints about the problem with units-in his treatment of the total costs as they depend on the particular quantities of the two variable inputs:

Denote the quantity of capital and of labor by $K$ and $L$, respectively, and their unit prices as $r$ and $w$. The total costs of using any volume of $K$ and $L$ is $C=r K+w L$, the sum of the costs of $K$ units of capital at $r$ per unit and $L$ units of labor at $w$ per unit.

We notice that in introducing total factor costs Ferguson uses the amorphous "units" and "per unit" rather than specifying just what those units are. If only on the basis of his choice of symbols, however, we might guess that the unit prices are the interest rate and the wage rate. However, the numerical illustration that immediately follows the quoted passage reveals our guess to be only half right: he supposes that "capital costs $\$ 1,000$ per unit $(r=\$ 1,000)$ and labor receives a wage of $\$ 2,500$ per man year $(w=\$ 2,500)$." So, now we see that labor-not surprisingly-is measured in man years. (We won't chastise Ferguson for the gender bias that was prevalent in 1966.) But capital is still measured in unidentified "units." We also see that $r$ is reckoned in dollars, which precludes its being the interest rate. Presumably, $r$ is the price (the rental price in the case of durable capital) of some physically defined unit of capital.

Roger Koppl has called to my attention the fact that in a later book (1969)
Ferguson dealt at some length with the issue of reswitching though not-it turns out-with the more fundamental issue of units. Ferguson bows to Cambridge, U.K.: "there is no doubt that the Cambridge Criticism is valid" (p. 269). But he continues to embrace "simple neoclassical theory" partly-with support from Murray Brown (1967)-on the belief that the applicability of the neoclassical relationships can be established on empirical grounds and partly-along with Samuelson-as a matter of faith. Samuelson had reaffirmed his commitment in the same year (and month!) his "Summing Up" appeared in print (1966b, p. 444): "Until the laws of thermodynamics are repealed, I shall continue to relate outputs to inputs-i.e., to believe in production functions."

The amorphous "unit" for capital is a red flag, indicating that there is no particular unit that recommends itself. I remember other such red flags from lectures at the University of Virginia-and from the literature on which those lectures were based. Marginal increases in the capital input were referred to as "hunks" of capital or "doses" of capital. Capital is by its nature heterogeneous-and more radically so than other inputs. The heterogeneity is reflected in the various physical measures: lumber is measured in board feet, concrete in cubic yards, steel in metric tons, gasoline in gallons, and electricity in kilowatt-hours. "Machinehours" are units that evoke some imagery of stereotypical capital equipment but hardly serve as a comprehensive unit. And capital in the sense of goods in process renders the issue of units hopelessly open-ended. What, then, is Ferguson's physically defined unit whose price is $\$ 1,000$ ?

Heterogeneity as a fundamental aspect of capital is emphasized by Ludwig Lachmann (1978 [1956]) and more recently by Peter Lewin (1999). The claim made here that capital is more radically heterogeneous than labor or land is not just a matter of a difference in degree. Different worker-hours of labor are not perfectly substitutable for one another. Neither are different acre-years of land. A substantial degree of heterogeneity, then, characterizes both of these factors of production. But our attempt to construct an analogous claim for capital is telling: different of capital are not perfectly substitutable for one another. The difficulty of even filling in the blank derives from capital's dimensional, or radical, heterogeneity. This is a point that the Cambridge, U.K. critics of neoclassicism themselves skirt-no doubt because it is as telling against their own constructions as it is against the neoclassicals. Taking capital to be dated labor, as in the rarified constructions of Samuelson and others, may serve their immediate purposes, but it fails to identify any general-purpose capital metric. We are tempted to paraphrase Cohen and Harcourt here: "What is the justification for a rarified unit of capital (dated labor) whose utilization is unwarranted outside the context of the most abstract models?"

Over the years, an immunizing pedagogical technique emerged in the classroom to deal with the problem of units. This technique, I suspect, was not at all unique to my Virginia experience. Instead of writing $Q=f(K, L)$, the professor 
would write $Q=f(A, B)$, where $A$ and $B$ were defined abstractly as two wellbehaved factors of production whose prices are $P_{A}$ and $P_{B}$. I remember catching the eye of a classmate as we both wondered just what sort of misbehavior was being ruled out. In subsequent lectures it was easy for the professor to shift the focus from $A$ and $B$ to $K$ and $L$-and to do so without bothering to reconsider the issue of "behavior." I learned only later that Samuelson in his "Summing Up" article used the phrase "well-behaved" to describe aspects of production theory that were not embroiled in the Cambridge paradoxes.

Though preemptively ruled out by Cambridge, U.K., the only solution to the problem of capital heterogeneity is the one recognized by Wicksell-recourse to that all-purpose common denominator: money. This is the solution that characterizes my own child's guide arithmetic and that reflects the methods of engineering economics. To fully capture the essence of capital investments, we must adopt as our common denominator not just money but rather time and money. So many dollars are tied up for so many years. The appropriate units are dollar-years. "Value over time" was the phrase that Yeager used in his lectures to express the nature of the capital input. With this solution, however, the price cannot be $r=\$ 1,000$ or $r$ = any other dollar amount. Rather, straightforward unit analysis dictates that the price, which by definition is measured in dollars per unit, must have the units of an interest rate.

$$
\text { PRICE }=\frac{\text { DOLLARS }}{\text { UNIT }}=\frac{\text { DOLLARS }}{\text { DOLLAR-YEARS }}=\frac{1}{\text { YEARS }}=\text { YEARS }^{-1}
$$

The price of a loan may be $10 \%$, that is, $\$ 0.10$ per dollar per year-or, equivalently, 0.10 years $^{-1}$. Similarly, the price of the factor of production that is measured in inverse years, generally expressed as an annual percentage rate (APR), is the rate of interest broadly conceived.

So conceived, the interest rate is the price of capital-or, as Cassel and Yeager would insist, the price of "waiting." The problem, here, as recognized and emphasized by Wicksell, stems from those dollars in the denominator. To illustrate with my Child's Guide, consider the dollar outlay of $\$ 210$ associated with Technique A. Supposedly, funds are borrowed-say, at $10 \%$ interest-and spent on real capital input of some kind-let's say a somewhat specific kind-at time $t_{1}$. In equilibrium, the rate of return on this capital would be that same $10 \%$. Now, suppose that market conditions (say, increased saving preferences) change such that the price of borrowed funds falls to $9 \%$. The interest rate has not fallen past a switch point, so technique $\mathrm{A}$ is still the technique of choice. But the price of the (physically defined) capital input will surely be bid up as a consequence of that same change in market conditions that lowered the rate of interest. That is, the value of the capital input used in period $t_{1}$ is now less heavily discounted than before. Hence, the higher dollar outlay required in this period is attributable in part to an increase in capital value not reflected in an actual increase in (physically defined) capital. This component of the increased outlay is called the Wicksell effect (Uhr, pp. 23-24 and 120-22)-and sometimes called the price Wicksell effect so as to provide a contrast with the real Wicksell effect (Burmeister, 1987, pp. 211).

The portion of the increase in the outlay attributable to the price Wicksell effect depends on the extent to which the capital input is stage-specific and on the remoteness in time to the subsequent revenues that the outlay makes possible. More definitively: (1) The greater the stage specificity, the greater portion of the change in outlay attributable to the price Wicksell effect. And (2) The greater the temporal distance between capital input and consumable output, the stronger the Wicksell effect (both price and quantity). As a summary reckoning, however, Casselian waiting, which has both a value and a time dimension, faithfully measures the factor of production whose price is the interest rate, while Fergusonian capital, whose price is $r=\$ 1,000$, remains unmeasurable.

Both the Wicksellian problem and the Casselian fix are pre-empted by the Cambridge U.K. conception of capital. Capital value never comes into play. With real capital (somehow) defined strictly in physical terms and with changes in the interest rate introduced as parametric changes (rather than responses to changed market conditions), the only possible "effect" is a change in technique. The rate of interest can fall from $800 \%$ to $8 \%$ without inducing any change at all in the economy's production process. (This dramatic decrease in the interest rate would affect only the distribution of income between capital and labor.) And if the interest rate drops below $8 \%$, the only change is the wholesale abandonment of Technique $\mathrm{A}$ and the adoption of Technique $\mathrm{B}$. The reverse change occurs if the interest rate drops below $2 \%$, the low-interest configuration being identical in all respects (except for the associated income distribution) to the high-interest configuration. This super-antiseptic quality of the reswitching "dynamics" is what identifies the Cambridge U.K. constructions as strictly comparative-statics exercises. There are no dynamics at all; there are only isolated economies in which Techniques $A$ and $B$ have the same present value at two different interest rates. If we take Joan Robinson's "Unimportance" article to heart, we must see that any account of the significance of the $2 \%$ and the $8 \%$ that employs a word ending in "ing" is bound to be misleading.

The neoclassical production function, however, is often put to use in the study of dynamics. It underlies growth theory as well as business cycle theory. The rate of interest is not itself parametric but rather is an endogenous variable that responds to parametric changes-in resource availabilities, technology, and saving preferences. Though the possibilities of reswitching may add a special twist to the problem of measuring capital, the problem remains even in the absence of the twist. Measuring capital summarily in physical dimensions, value dimensions, or amorphous dimensions each have their failings. As measures of aggregate capital, 
dollars per machine-hour, dollars per dollar-year, and dollars per dose serve as warnings about the problems rather than as solutions to them.

A satisfactory solution, in my judgment, requires a theory that (1) takes explicit account of the time dimension in the production process and (2) takes the interest rate as a market-determined allocator of saving among different, temporally defined uses.

\section{A Time-Dependent Capital Reckoning}

Cohen and Harcourt simply reject the neoclassical theory, with its paradox-riddled aggregate production function. They offer as a viable alternative the classical theory of Ricardo and Sraffa, with its attention to class and the allocation of the surplus. In his "Summing Up" article, Samuelson deals with the neoclassical and Austrian views of production, focusing importantly on the time dimension of the production process as set out by the Austrians. He refers to Böhm-Bawerk no fewer than sixteen times and mentions the Austrians more broadly another ten times. If the Austrian-fashioned sequence of inputs exhibits reswitching, then the neoclassical capital-to-output ratio (and the aggregate production function) entails misbehavior of the (physically defined) capital input. In his concluding section, Samuelson is not inclined to recommend a return to classical modes of thought. Instead, he waxes philosophical about "scholars [not being] born to live an easy existence" (p. 583).

Surely, the relevant contrast is not that between classical theory and neoclassical-cum-Austrian theory. It is rather that between neoclassical theory, in which capital is aggregated for inclusion in a production function, and Austrian theory, in which capital is temporally disaggregated in order to account for movements of capital within a capital structure. Especially in view of the fact that capital-or waiting-has two dimensions (value and time) that can change in different proportions depending upon the particulars of the case, it is critical to maintain the distinctions among the various temporally defined capital inputs.

As Cohen and Harcourt (2003a, p. 200) recognize, the neoclassical production function continues to be used today-in endogenous growth theories and in real business cycle theory. Tellingly, this particular piece of neoclassicism was introduced into modern macroeconomic thought as a foil against which to promote the Keynesian mode of thinking. A quarter of a century after the appearance of the General Theory, Gardner Ackley (1961) recreated pre-Keynesian thought by combining the production function with a supply-and-demand-determined employment level and a quantity-of-money-determined price level. Employing the familiar $Q=f(K, L)$, where the capital input $(K)$ is given, Ackley showed that labor-market conditions determine employment and hence real output and real income and that the additional consideration of the quantity of money allows for the determination of the nominal levels of the output and income magnitudes. The
Ackley-based rendition of Keynes versus the classics continues to be served up as standard textbook fare, while a blending of Keynes and the classics (Keynesianneoclassical synthesis) is presented in the form of Keynesian IS-LM analysis with a supply-side (neoclassical) undergirding.

Here and in the discussion below, the term "classical" is used as Keynes used it-to refer to the ideas of all economists (except Robert Malthus) from Adam Smith to Cecil Pigou. Accordingly, the loanable-funds market, in which the interest rate brings into balance the supply of loanable funds (saving) and the demand for loanable funds (to finance investments) is taken to be the centerpiece of "classical" economics. This application of supply-and-demand analysis would have no place in Ricardo's Principles of Political Economy (1817 [1911]) or in Sraffa's Production of Commodities by Means of Commodities (1960).

Though Ackley's trumped-up classical model employing the neoclassical production function is now commonplace, the understanding of how this model actually relates to classical, neoclassical and Austrian thought has been largely lost. Ackley himself recognized the nature-though, I will argue, not the significance-of the simplifying assumptions needed to transform pre-Keynesian thought into a classical model. The introduction of his graphical exposition of classical fullemployment equilibrium, especially his second-listed simplifying assumption, is revealing:

Actually, Classical price theory (as opposed to monetary theory) implies that the volume of employment and output is determined in the first instance not by the level but by the structure of prices.... We shall simplify this part of the analysis very greatly by assuming (1) that perfect competition prevails in all industries; and (2) that each industry is vertically integrated: it hires only labor and produces final output (using a given stock of capital goods and natural resources); there are no intermediate goods. These assumptions can be removed with no major change in results... (Ackley, 1961, p. 124, emphasis altered).

Here, Ackley has collapsed the critical time element out of the Austrians' capital structure. The movement of resources among the temporally sequenced stages of production is no part of Ackley's classical story. Tellingly, the rate of interest, which in the Austrians' own theorizing equilibrates the loanable-funds market, broadly conceived, and hence governs the intertemporal allocation of resources, makes no appearance in his classical model. Ackley presents separately the loanable-funds theory, never integrating-or reconciling-this staple of preKeynesian macroeconomics with the production function and its "given" capital stock.

Despite Ackley's claim to the contrary, actually allowing for an intertemporal structure of capital does produce a "major change in results." It allows for differential changes in the value of capital in response to a change in the rate of interest. The so-called Wicksell problem, though still a problem for those who insist on a purely physical measure of capital, is actually an important part of the market mechanism that translates intertemporal consumption preferences into 
intertemporal production activities. For instance, consider an increase in saving, which depresses interest rates and shifts consumer buying power into the future. The lower borrowing costs get translated through present-value reckonings into changes in the relative values of capital in each of the temporarily sequenced stages of production. Engineering Economics tells us that present values all rise-some more than others. A more thoroughgoing economic understanding allows us to see that the increase in the present values of early-stage capital relative to the present values in late-stage capital results in resources being reallocated in the direction of the earlier stages. And this pattern of capital reallocation is the very one needed to shift the economy's output further into the future and hence to accommodate the change intertemporal preferences.

Increased demands for capital having higher present values will be partly accommodated by increased allocations and partly choked off by increased prices. We note that it is specifically in this connection that the Austrians have long emphasized that capital is heterogeneous. It is not surprising, then, that no summary statement can be made-or need be made-as to just how large the real response might be relative to the price response. For capital of low specificity, the ultimate price response is minimal, though during the adjustment period it is precisely the increase in prices that attracts the additional capital; for highly specific capital, the price response may dominate.

It may be true that once the market has adapted itself to an increase in saving, the shifted neoclassical production function, $\left[Q=f\left(K^{\prime}, L\right)\right.$ instead of $\left.Q=f(K, L)\right]$, is one that has a greater capital input and hence allows for a greater aggregate output. But in Ackley's model, the significance of the capital structure-and the associated market process-is in total eclipse. As Hayek (1941, p. 147) insisted, “A given stock of capital goods does not represent one single stream of potential output of definite size and time shape; it represents a great number of alternatively possible streams of different shapes and magnitudes" (p. 147).

The absence of any accounting of the intertemporal capital structure and of the market process that maintains that structure or modifies it in response to preference changes is even more telling against Ackley's timeless classical model when the issue is policy-induced (rather than preference-induced) changes in the rate of interest. Suppose, for instance, that the central bank injects additional sums of money through credit markets, lowering interest rates and eventually raising prices all around. The inattention to the market process in this case yields profoundly misleading conclusions. In Ackley's classical model, long-run results get undue emphasis in the light of short-run aspects of the market process.

With the loanable-funds market relegated to side-show status, the focus is on the relationship between the money supply and the overall price level as implied by the quantity theory of money (MV = PQ). The injection of new money through credit markets (a greater $M$ ) leads ultimately to increased prices of both consumer goods and investment goods (a higher $\mathrm{P}$ ). There are no lasting real effects of a monetary injection. The $Q=f(K, L)$ of the post-injection equilibrium is the same $Q=f(K, L)$ that characterized the pre-injection equilibrium.

A very different conclusion emerges if the effects of the increased money supply are tracked by the loanable-funds theory rather than by the quantity theory. The monetary injection increases the supply of loanable funds and hence lowers the rate of interest. The amount of investment funds demanded increases, especially in the early stages of production. But with no change in intertemporal preferences, the amount of saving actually decreases-in response to the lower rate of interest. (Savers move down along an unshifted supply curve.) And less saving, of course, means correspondingly greater demands for current consumption. The market process that allocates resources within the economy's capital structure is at war with itself. The changing pattern of resource allocation, which entails an increased commitment to serving future demands while also accommodating current demands, is inherently unsustainable. The eventual-and inevitable-reversal of the capital restructuring in the face of increasingly binding resource constraints is anything but a side show. Given the heterogeneity of capital and the durability and specificity of some early-stage capital, the policy-induced boom and subsequent bust can leave the economy's productive capacity well below its pre-injection level. The distorted $Q=f\left(K^{\prime}, L\right)$ doesn't morph back to the original $Q=f(K, L)$ in a timely fashion. The long run in which the original structure recreates itself on the basis of actual intertemporal preferences may be long indeed.

\section{Choosing Among Frameworks}

As it turns out, the neoclassical production function is condemned by both Cambridge, UK and the Austrians-but for very different reasons. The Cantabrigians condemn a blend of neoclassical and Austrian ideas. They insist on a physically defined capital input and then argue that potentially anomalous changes in the interest rate and in the degree of roundaboutness undermine the logic of the neoclassical production function. The Austrians, who insist that the capital input has a value dimension, hold to the claim that the degree of roundaboutness and the rate of interest are inversely related. They are not moved by counterexamples involving a physically defined capital input. A reduction in interest rate increases the demand price for early-stage capital. But quite independent of the potential for technique reswitching, which F. A. Hayek recognized early on (Hayek, 1941, pp. 76-77, 140-45, 191-92 and passim), the Austrians are critical of the neoclassicals for compressing the temporally defined stages of capital into an all-inclusive $K$ and hence concealing the differential changes in capital values. The charge that Hayek (1931a, p. 277) leveled against John Maynard Keynes applies equally well to the neoclassicals: "[Their] aggregates conceal the most fundamental mechanisms of change."

Finally, it can be noted that the action item announced boldly by Cohen and 
Harcourt-a return to the Ricardo and Sraffa's classical way of thinking-comes as no news to the Austrians. Ludwig Lachmann (1986, p. 227) saw the general thrust of the Cohen-Harcourt message in an early article by Sraffa: "With benefit of hindsight we are now able to understand that Sraffa's [1932] critique of Hayek's book [Prices and Production [(1931b), in which the intertemporal structure of production loomed large] marked the start of the neo-Ricardian counterrevolution.... The aim of [this] counter-revolution is to undo the subjectivist revolution in economic thought which took place in the 1870 s, led by Jevons, Menger and W alras...." An important difference between Sraffa (1932) and CohenHarcourt (2003a) is that Sraffa offered up his critical remarks while disguising his own preference for the Ricardian way of thinking, which had fallen into disfavor many decades earlier. Lachmann (p. 228) explains: "The reason for the disguise he chose to wear is obvious.... The neo-Ricardian counter-revolution, in the circumstances of 1932, could not be expected to win adherents.... For his polemical purpose it was better that [his readers] should be puzzled than that they might become suspicious."

If the 1932 Sraffa article can be seen as marking the start of the neo-Ricardian revolution, we might wonder if in years to come the 2003 Cohen-Harcourt article will be seen as marking the end of it. The lack of a substantive answer to the "Whatever Happened?" question and the lack of appeal of the Ricardo-Sraffa way of thinking may give just such a special significance to 2003 .

The thrust of the present paper is that the alternative framework that Sraffa hid and that Cohen and Harcourt proudly advertise is a false one. We need not choose between Ricardo's classical framework and some neoclassical-cum-Austrian framework. This overly constrained two-way choice becomes a three-way choice once we recognize that each of the three schools here is sufficiently distinct in terms of the perceived nature of the rate of interest and the role of the interest rate in achieving a coordination of consumer preferences and production activities.

The neoclassical school allows for a market determination of the interest rate (the loanable-funds theory) but does not allow for changes in the interest rate to have any significant effect of the intertemporal structure of capital. Ricardian classicism allows for changes in the interest rate to affect the intertemporal structure of capital-though only through a switching of techniques and possibly a subsequent reswitching-but treats the interest rate itself as if it were determined outside the framework of analysis. The Austrian theory allows for a market determination of the interest rate and allows for changes in the interest rate to govern the intertemporal allocation of resources within the economy's capital structure. In fact, these two features are actually two perspectives on a single feature. Intertemporal exchanges in the marketplace-whether directly registered in the market for loanable funds or indirectly registered as a change in the price of early-stage capital relative to late-stage capital-work to coordinate the production decisions in the various temporally defined stages with intertemporal consumption preferences.

We can reject the idea that writing $Q=f(K, L)$ somehow allows us to ignore the composition of the capital structure. Further, with ample support from Leland Yeager, we can reject the claim that the intertemporal structure of capital must be specified in physical terms and not value terms. Technique reswitching, a possibility that hinges critically on a physical measure of capital has little claim on our attention. And the insight that a change in the degree of roundaboutness, brought about by a change in saving and reckoned in value terms as the movements of resources among the stages of production, cannot be made meaningless by the Cambridge polynomials and cannot be marginalized by the neoclassical $K$.

\section{Bibliography}

Ackley, Gardner. (1961) Macroeconomic Theory, Toronto: Macmillan.

Bermeister, Edwin (1987) "Wicksell Effects," in John Eatwell, Murray Milgate, and Peter Newman, eds. The New Palgrave Dictionary of Economics, vol. 4, pp. 910-912.

Brown, Murray (1967) "Substitution-Composition Effects, Capital Intensity Uniqueness and Growth," Discussion Paper \#2, Economic Research Group, State University of New York at Buffalo.

Cohen, Avi J. and Geoffrey C. Harcourt (2003a) "Whatever Happened to the Cambridge Capital Controversies?” Journal of Economic Perspectives, vol. 17 no. 1 (Winter), 2003, pp. 199-214.

Cohen, Avi J. and Geoffrey C. Harcourt (2003b) "Cambridge Capital Controversies: Response from Avi J. Cohen and G. C. Harcourt," Journal of Economic Perspectives, vol. 17, no. 4 (Fall) 2003, pp. 232-33.

Ferguson, C. E. (1966) Microeconomic Theory. Homewood, Ill.: Richard D. Irwin, Inc

Felipe, Jesus and J. S. L. McCombie (2003) "Cambridge Capital Controversies: Comment," Journal of Economic Perspectives, vol. 17, no. 4 (Fall) 2003, pp. 227-28.

Garrison, Roger W. (1979) "Waiting in Vienna," in Mario J. Rizzo, ed., Time, Uncertainty, and Disequilibrium, Lexington, Mass: D. C. Heath and Co., pp. 215-226.

Greenfield, Robert (2003) "Cambridge Capital Controversies: Comment," Journal of Economic Perspectives, vol. 17, no. 4 (Fall) 2003, pp. 228-29.

Hayek, Friedrich A. (1931a) "Reflections on the Pure Theory of Money of Mr. J. M. Keynes," Economica, vol. 11, no. 33 (August), pp. 270-295.

Hayek, Friedrich A. (1931b) Prices and Production. London: George Routledge and Sons.

Hayek, Friedrich A. (1941) The Pure Theory of Capital. Chicago: Chicago University Press.

Lachmann, Ludwig M. (1978 [1956]) Capital and Its Structure. Kansas City: Sheed, Andrews, and McMeel. 
Lachmann, Ludwig M. (1986) "Austrian Economics Under Fire: The Hayek-Sraffa Duel in Retrospect," in Wolfgang Grassl and Barry Smith, eds., Austrian Economics: Historical and Philosophical Background. New York: New York University Press.

Lewin, Peter (1999) Capital in Disequilibrium: The Role of Capital in a Changing World. London: Routledge.

Maddox, Rodney and Michael Carter (1982) “A Child's Guide to Rational Expectations," Journal of Economic Literature, vol 20, no. 1 (March) pp. 39-51.

Robinson, Joan (1975) “The Unimportance of Reswitching." Quarterly Journal of Economics, vol. 89 no. 1 (February), pp. 32-39.

Samuelson, Paul A. (1962) "Parable and Realism in Capital Theory: A Surrogate Production Function," Review of Economic Studies, vol. 29, no. 3 (June), pp. 193-206.

Samuelson, Paul A. (1966a) "A Summing Up," Quarterly Journal of Economics, vol. 80, no. 4 (November), pp. 568-583.

Samuelson, Paul A. (1966b) "Rejoinder: Agreements, disagreements, doubts, and the case of induced Harrod-neutral technical change, Review of Economics and Statistics vol. 48, no. 4 (November) p.444. Sraffa, Piero (1932) “Dr. Hayek on Money and Capital," Economic Journal, vol. 42, no. 165 (March), pp. $42-43$.

Sraffa, Piero (1960) The Production of Commodities by Means of Commodities. Cambridge: Cambridge University Press.

Ricardo, David (1911 [1817] On the Principles of Political Economy and Taxation. New York: E. P. Dutton and Co.

Uhr, Carl G. (1960) Economic Doctrines of Knut Wicksell, Los Angeles: University of California Press. Walsh, Vivian and Harvey Gram, Classical and Neoclassical Theories of General Equilibrium: Historical Origins and Mathematical Structure. Oxford, U.K.: Oxford University Press. 1980.

Wicksell, Knut (1934 [1911]) Lectures on Political Economy. Vol. 1, London: George Routledge and Sons.

Yeager, Leland B. (1979) "Capital Paradoxes and the Concept of Waiting." in Mario J. Rizzo, ed., Time, Uncertainty, and Disequilibrium, Lexington, Mass: D. C. Heath and Co., pp. 187-214.

Yeager, Leland B. (1976) “Toward Understanding Some Paradoxes in Capital Theory,” Economic Inquiry, vol. 14, no. 3 (September), pp. 313-346. 